Artículo de investigación

Cuestiones de Filosofía

ISSN: 0123-5095

E-ISSN: 2389-9441

Vol. $3-\mathrm{N}^{\mathrm{o}} 21$

Junio - diciembre, año 2017

pp. 107-132

\title{
Performatividad y afectos ${ }^{1}$
}

\author{
Performativity and Affections
}

\section{Luz Helena Di Giorgi-Fonseca}

Universidad del Rosario, Colombia

Recepción: 30 de marzo del 2017

Evaluación: 15 de mayo del 2017

Aceptación: 4 de junio del 2017

\footnotetext{
1 El artículo hace parte de la revisión teórica, vinculado a la investigación doctoral que realizar la autora, que se titula: Análisis de las formas de agencia campesina conformadas con El Paro Nacional Agrario y Popular (PNAP) ocurrido en el 2013. Un acercamiento desde las representaciones simbólico-afectivas que se ponen en tensión con el ejercicio del derecho y la movilización social. Esta investigación se realiza para el Doctorado en Derecho en la Universidad del Rosario. En los últimos meses el nombre de la investigación fue modificado: Análisis de las formas de agencia política-jurídica campesina conformadas con El Paro Nacional Agrario y Popular (PNAP) ocurrido en el 2013. Un acercamiento desde las representaciones simbólico-afectivas que se ponen en tensión con el ejercicio del derecho y la movilización social
}

Performatividad y afectos,

Luz Helena Di Giorgi-Fonseca- p. 107-132 


\title{
Resumen
}

Un tema transversal que aparece en la obra de la filósofa Judith Butler, especialmente en Vida precaria y Marcos de guerra, tiene que ver con la experiencia afectiva que tienen los sujetos. Por esta razón, el objetivo del presente artículo teórico es analizar la manera como la filósofa norteamericana trata el tema de los afectos o las emociones. El texto se centra en demostrar la pertinencia de la reflexión en torno a los afectos, ya que es un elemento crítico-social que ayuda a comprender la constitución de la subjetividad y la agencia, tanto individual como colectiva; asimismo, pretende ofrecer nuevos aportes para el entendimiento de las situaciones contemporáneas de discriminación y opresión, pero también de resistencia en contextos democráticos. Aun cuando el sujeto, desde sus experiencias afectivas, se encuentra condicionado por los marcos normativos sociales, es posible pensar en luchas desde el afecto, como una salida ante los efectos restrictivos que este genera.

Palabras clave: Performatividad; afectos; crítica; discriminación; opresión; ontología social; agencia.

\begin{abstract}
A cross-cutting issue that appears in the work of the philosopher Judith Butler, especially in Precarious Life and Frames of War has to do with the affection experience that subjects have. For that reason, this theoretical article seeks to analyze how the North American female philosopher addresses affection and emotions-related issues. The text focuses on showing how pertinent it is to reflect on affection, since it is a critique-social element that helps to understand subjectivity constitution and agency, individual as well as collective. Likewise, it seeks to provide new contributions for understanding contemporary situations of not only discrimination and oppression, but also resistance in democratic contexts. Even when a subject, from his/her affective experience, is conditioned by social legal frameworks, it is possible to thinks of affection struggle as an escape from the restrictive effects it generates.
\end{abstract}

Key words: Performativity; affection; critique; discrimination; oppression; social ontology; agency. 


\section{INTRODUCCIÓN}

“(...) cuando hablamos de duelo abierto o indignación, estamos hablando de unas reacciones afectivas que están sumamente reguladas por regímenes de poder $y, a$ veces, sometidas a censura explícita".

(Butler, 2010:66).

Uno de los grandes aportes que ha hecho Judith Butler al debate feminista tiene que ver con la configuración de la teoría de la performatividad de género. Por medio de un análisis genealógico, muestra la manera como los cuerpos asumen, a través de prácticas regulatorias o "materialización corporal", su identidad sexual. Ella hace evidente cómo bajo la determinación de marcos de inteligibilidad o normativos ${ }^{2}$ se constituyen, comprenden y narran los sujetos, bajo una lógica diferencial heteronormativa. No obstante, esta "materialización corporal" se lleva a cabo bajo unas condiciones afectivas que, de forma silenciosa, establecen y tramitan las normas sociales. En este sentido, tal constitución subjetiva es posible a partir de una manipulación de la experiencia afectiva de los sujetos que, en principio, se cree individual y espontánea. Por esta razón, el presente artículo se centra en ver cómo los marcos normativos de exclusión configuran la disposición afectiva, en este caso, la idea es ver por qué la capacidad del duelo, como lo sugiere la cita establecida al inicio de la presente introducción, depende de una facultad de percepción que no es deliberada, sino que se encuentra determinada por unos marcos de interpretación, que se reproducen a través de ciertos dispositivos de poder como las instituciones privadas o públicas y los medios de comunicación, entre otros.

El objetivo de este documento es analizar el rol que desempeñan los afectos en esta lógica comprensiva del marco de inteligibilidad que describe Butler, además de esclarecer el papel que tienen los mecanismos de distribución afectiva en la agencia de los sujetos en contextos de exclusión. Para este último punto, se abordarán los planteamientos realizados por Iris Marion Young, quién hace un estudio de los contextos contemporáneos de opresión. Ella

\footnotetext{
2 Los marcos de inteligibilidad o normativos de exclusión se refieren a aquellas construcciones que desde un discurso hegemónico determinan el tipo de conductas que el cuerpo debe acatar como normales; para ello se necesita una elaboración legal y una práctica regulatoria. A propósito de la adjudicación del sexo, la autora afirma: “(...) 'el sexo' no sólo funciona como norma, sino que además es parte de una práctica reguladora que produce los cuerpos que gobierna, es decir, cuya fuerza reguladora se manifiesta como una especie de poder productivo, el poder producir — demarcar, circunscribir, diferenciar - los cuerpos que controla" (Butler, 2002:18).

Performatividad y afectos,

Luz Helena Di Giorgi-Fonseca- p. 107-132 
muestra cómo en sociedades liberales, aun cuando las personas consideran legítimo el principio de igualdad, existen prácticas discriminatorias y opresivas que se expresan a través de los afectos que experimentan las personas frente a la diferencia, específicamente, en acciones cotidianas inconscientes, que no se cuestionan.

Para tal fin, se reflexionará acerca de los siguientes puntos: en primer lugar, se hará una reconstrucción de la noción de performatividad y de los marcos de exclusión en la obra de Butler; en un segundo momento, se analizará la experiencia afectiva implicada en los planteamientos que hace esta autora, especialmente en su texto Marcos de guerra, y cómo esta disposición explica las nuevas situaciones de opresión que experimentan los grupos sociales en sociedades liberales; finalmente, se plantearán argumentos sobre la relación que existe entre agencia y disposición afectiva, considerado el primer aspecto de la relación como un elemento crítico-social, a partir de la noción de ontología social que propone Butler.

La última parte del documento hace énfasis en la pertinencia de dirigir la mirada a la disposición afectiva como elemento crítico-social, pues posibilita hacer nuevas reflexiones para el tema de la subjetividad y la agencia. Esto se debe a que, en Marcos de Guerra, Butler considera que, aun cuando el sujeto desde sus experiencias afectivas se encuentra condicionado por los marcos de inteligibilidad, es posible pensar en luchas o resistencia desde el afecto como salida a los efectos restrictivos que este genera. Para Butler, el ejercicio crítico no hace referencia a la formulación de un juicio de valor acerca de las circunstancias de un hecho social, sino a la elaboración de una serie de preguntas que tienen que ver con la búsqueda de las relaciones que existen entre el saber y poder, en tanto que, a partir de allí es posible evidenciar los límites de ciertas certezas epistemológicas que configuran un tipo de ordenamiento social, pero que también generan zonas de exclusión. Al respecto afirma: "Es desde esta condición y a través de una rasgadura en el tejido de nuestra red epistemológica que la práctica de la crítica surge, con la conciencia de que ya ningún discurso es adecuado o de que nuestros discursos reinantes han producido un impás" (Butler, 2008:147). En este sentido, la tarea crítica consiste en identificar las formas de racionalidad y representación que generan exclusión y opresión.

\section{Performatividad y Marcos de exclusión}

Butler hace una caracterización paradójica del marco ontológico-epistemológico que configura las formas de vida y las condiciones que la hacen cog- 
noscible. Desde un punto de vista genealógico, ella muestra, por un lado, el modo como los cuerpos se someten a la norma y, por el otro, la forma en que este sometimiento revela un proceso de materialización que hace inteligible a los cuerpos. En Género y disputa, por ejemplo, el género y el sexo no responden a un acto de voluntad, sino que revelan un proceso de regulación a partir de prácticas reiterativas, por el que los individuos se hacen viables en el contexto heteronormativo. En este sentido, la teoría de la performatividad devela: 1) las formas de constitución del ser y los elementos que permiten hacer cognoscible una vida; 2) cómo el proceso de materialización se manifiesta a partir de una reiteración o interpretación de las normas, que no implica una voluntad, ni un determinismo absoluto; y 3) la manera como las normas y las prácticas sociales nos hacen inteligibles, tanto para sí mismos como para los otros.

A la hora de hablar de la génesis de la noción de género, en Cuerpos que importan, la autora sugiere pensar la noción más como un proceso de materialización que como una elaboración constructiva, dado que esta última perspectiva implica, para posturas feministas como la de Simone de Beauvoir, una relación causal entre la cultura y la naturaleza. Las posturas feministas, guiadas por las consideraciones de Beauvoir de forma implícita, consideran que la cultura ejerce una acción sobre la naturaleza que, por lo demás, se cree pasiva. Bajo este enfoque, el género adquiere una significación social, mientras que el sexo asume una caracterización natural y anterior a una posible significación; por esta razón, el discurso constructivo supone una impresión masculinista en la naturaleza pasiva femenina. Si esto es así, o bien el sexo es anterior a cualquier construcción, o su comprensión conlleva una construcción ficticia.

Butler quiere romper con estos supuestos, pues considera que la noción de naturaleza tiene una propia historia; de allí que retome la noción de materia, que hace alusión a un proceso “(...) que se estabiliza a través del tiempo para producir el efecto de frontera, de permanencia y de superficie que llamamos materia" (Butler, 2002:28). Este proceso sugiere un acto temporal que permite, a partir de la reiteración de normas, la producción del sexo. La autora piensa esta perspectiva a la luz de la noción de ideal regulatorio, que refiere a prácticas iterables ${ }^{3}$ que permiten la aparición de la subjetividad en la esfera pública.

\footnotetext{
3 Las prácticas iterables hacen referencia a aquellos actos reiterativos, mediante los cuales el discurso produce los efectos que nombra. Para ampliar este punto, es importante revisar el texto de J. Butler. Ver Introducción y Primer capítulo en Cuerpos que importan.

Performatividad y afectos,

Luz Helena Di Giorgi-Fonseca- p. 107-132 
Hay que advertir que, no solo regulan la diferencia sexual, también orientan el ideal de raza y modos de ser. En el contexto legal, por ejemplo, sugiere Butler, para seguir a Michael Foucault (1976), se crean procesos de subjetivación que producen la identidad, para unos individuos que luego quieren representar desde un punto de vista político. En este sentido, la noción de sujeto es importante para el ejercicio del derecho pues, bajo esta categoría, se adjudican y garantizan derechos. Sin embargo, la forma como lo hacen puede llegar a ser problemática, pues las políticas podrían estar formuladas bajo representaciones discriminatorias y opresivas, más aún en un contexto en el que los procesos de subjetivación se hacen a partir de marcos normativos que producen la identidad. En este caso, la subjetividad es construida, establecida, desde instancias dominantes que no tienen en cuenta los grupos sociales a los que dicen referirse. Respecto a esta situación, Judith Butler (2007), al comentar acerca de Foucault, asegura: "Las nociones jurídicas de poder parecen regular la esfera política en términos negativos, es decir, mediante la limitación, la prohibición, la reglamentación, el control y hasta la protección de las personas vinculadas a esa estructura política a través de la operación contingente y retractable de la elección" (p. 47). Por ejemplo, el Estado colombiano ha gestionado la alteridad campesina por medio de dos categorías: "trabajador agrario" y "pequeño productor". Estas nociones, desde su carácter simbólico, responden a una imagen homogenizada de las personas ubicadas en la frontera con lo urbano ${ }^{4}$. Bajo esta condición, las

\footnotetext{
${ }^{4}$ No se tiene el dato exacto del total de personas campesinas que viven en Colombia, debido a que los instrumentos encargados, en este caso el DANE (Departamento Administrativo Nacional), consideran que la noción de "campesino" es ambigua. Por esta razón, el Censo realizado en el 2005 hace una división entre "los centros poblados" o "cabeceras" y las zonas rurales como "el resto", cuya justificación se encuentra en la Ley 388 de 1997, que contempla que el suelo rural es aquel que no es apto para el uso urbano, pero sí para la producción agrícola, ganadera o forestal y explotación de recursos naturales. Bajo estas indicaciones, se dice que el $75 \%$ población es urbana y el $25 \%$ restante es rural: alrededor de 31,5 millones de personas viven en las "cabeceras" y 10,5 millones de personas en el "resto". El informe del desarrollo humano (PNUD, 2011) asegura que esta categoría no es adecuada para expresar lo "rural", debido a que: "En estricto sentido, urbano y cabecera no son lo mismo pues tanto la economía como las relaciones sociales de la mayoría de pequeñas cabeceras municipales están asociadas con el campo o con actividades típicamente agropecuarias. De acuerdo con su actividad económica dichas cabeceras podrían ser calificadas como rurales. Por otro lado, en zonas como el Oriente antioqueño - que en las estadísticas nacionales forma parte del resto- se observan procesos industriales de alta tecnología. De allí se sigue que tampoco sería válido identificar lo rural con el resto. La categoría "resto" no es adecuada para expresar lo rural, ni por actividad económica, ni por relaciones sociales y espaciales. Así, la distinción entre cabecera y resto, que pone el énfasis en el número de habitantes ('núcleo de población', como lo llama el DANE), desconoce la dimensión territorial" (p. 53).
} 
poblaciones campesinas sufren los efectos del sentido que en el ámbito político-jurídico se le ha dado a estos conceptos, pues este tiene un impacto en la forma como estas personas se comprenden a sí mismas, cómo la perciben los otros y, específicamente, cómo se gestionan y son adjudicadas sus necesidades. Contrario a esta caracterización, el campesinado colombiano está constituido por grupos heterogéneos ${ }^{5}$ que se distinguen por sus relaciones sociales, creencias, los vínculos con alguna etnia, el territorio que ocupan (aquellos que tienen tierra y quienes no), cómo ocupan el espacio rural ${ }^{6}$ y su racionalidad económica y productiva, entre otros aspectos.

Los individuos que no responden a estos ideales regulatorios, como en el caso sugerido, son excluidos, considerados como seres abyectos o personas que no entran dentro de la inteligibilidad normativa: "Lo abyecto designa aquí precisamente aquellas zonas 'invivibles', 'inhabitables' de la vida social que, sin embargo, están densamente pobladas por quienes no gozan de la jerarquía de los sujetos, pero cuya condición de vivir bajo el signo de lo 'invivible' es necesaria para circunscribir la esfera de los sujetos (Butler, 2002:20).

\footnotetext{
5 En las distintas regiones de Colombia existen poblaciones campesinas que culturalmente se distinguen por la forma como constituyen su modo de ser, según las características que posee el territorio en donde se asientan. Un ejemplo de ello lo evidencia el texto realizado por el Grupo de Investigación de la Universidad de la Salle, titulado: La familia rural y sus formas de diálogo en la construcción de paz en Colombia, en el cual consideran, para seguir a Carneiro (2008), que "las maneras de posicionarse en un espacio reconocido como rural también varían según la posición social de los individuos en este sistema social cada vez más heterogéneo" (p. 96). Bajo esta perspectiva, por ejemplo, señalan las diferencias que de sí mismas conciben las personas que habitan diferentes regiones del país. Se da el caso de la diferencia que existe entre las personas pertenecientes a la región del pacífico y la zona andina: "Mientras en Quinamayó la identidad grupal pasaba por el eje de la etnia (con sus apellidos y su pasado de opresión implícito), en la vereda andina la identidad se puede ver condensada más bien en una forma de la relación atravesada por un producto de montaña: el café" (p. 81).

6 Jaime Forero et. al. (2010) hace una clasificación de la ocupación productiva del espacio rural, en la que tiene en cuenta las interrelaciones que hay entre la producción familiar y otros agentes económicos (productores empresariales) y la expansión de latifundismo como la formación del capitalismos agrario, de la siguiente manera: 1) Espacios de "capitalismo rural": la empresa familiar coexiste y tiene relaciones con la empresa capitalista. En este caso, se presentan asociaciones entre las cuales uno aporta la tierra y los costos del cultivo, mientras el otro aporta el trabajo; por ejemplo, "la producción cebollera del lago de Aquitania y quizás la mayor parte de las zonas hortofrutícolas y paperas" (75). 2) Espacios de "capitalismo agrario", dado que la empresa capitalista ha homogeneizado el paisaje socio-productivo; ejemplos de esto son: la producción azucarera en el Valle del Cauca, del banano en Urabá y la producción de palma. 3) Espacios en los que confluyen grandes, medianos y pequeños productores. 4) Espacios campesinos en los que predomina la agricultura familiar. 5) Espacios de disputa entre latifundistas y comunidades campesinas. 6) Espacios de colonización. 7) Espacios de comunidades indígenas y afro americanas.
}

Performatividad y afectos,

Luz Helena Di Giorgi-Fonseca- p. 107-132 
Esas zonas "invivibles", "inhabitables", representan el límite de la identidad pero, paradójicamente, se convierten en un recurso para la legitimidad simbólica. Esto quiere decir que el carácter epistemológico que ofrece el marco de inteligibilidad enmarca y clasifica la aparición de los individuos en el terreno de lo simbólico, lugar en el que estos son inteligibles y reconocidos a través de condiciones, que permiten aprehender la vida y las formas como se percibe a la otredad.

Los marcos de inteligibilidad, de alguna manera, crean una imagen de las personas, que luego intentan imponer en ellas. Ser enmarcado, to frame ${ }^{7}$, significa ser representado o interpretado falsamente, pues el marco configura a los individuos bajo un esquema de interpretación que amplía o disminuye la imagen que hace posible la aparición de los sujetos en el terreno de lo simbólico, legítimo o cognoscible. No obstante, esta imagen no tiene nada que ver con los individuos que dice representar, pues "el marco nunca determinaba del todo eso mismo que nosotros vemos, pensamos, reconocemos y aprehendemos. Algo excede al marco que perturba nuestro sentido de la realidad (...)" (Butler, 2010:24).

Ser enmarcado implica un proceso de aprehensión y reconocimiento, que oscila entre la capacidad perceptiva que tienen las personas con los otros es decir, la manera como las personas reconocen a las otras por medio de la afección que genera el encuentro-y los esquemas históricos que configuran el ámbito de lo cognoscible ${ }^{8}$. En la aprehensión, la percepción del otro aún no involucra elementos que permiten el reconocimiento, debido a que es una experiencia que está asociada al encuentro afectivo con el otro, más que a unos criterios conceptuales de interpretación. El reconocimiento, por el contrario, sugiere unos elementos de inteligibilidad que involucran esquemas conceptuales tradicionales que determinan el ámbito de lo cognoscible. El marco no es un esquema estático o inmodificable. Por su función iterable, esta entidad circula y se establece en una lógica temporal en la que, si se tienen las condiciones de reproducibilidad, logra su fin. Sin embargo, puede romperse, y lo

\footnotetext{
7 Término utilizado por Butler en Marcos de Guerra.

8 Butler, en el texto Marcos de Guerra, hace una distinción entre aprehender y reconocer una vida. Aprehender una vida implica un ejercicio ambiguo, en tanto que es una especie de reconocimiento, que no se hace de modo completo, en tanto que, únicamente se manifiesta a través de los afectos que emergen en el momento del encuentro con los otros. Las formas de reconocimiento, por el contrario, implican un sistema conceptual, normas fundamentadas en aparatajes epistemológicos que clasifican y determinan qué cuenta o no como vida. Hay que advertir que las formas de aprehensión pueden ser base para la crítica de reconocimiento. Este punto se ampliará al final del texto.
} 
hace debido a su constancia y necesidad de aterrizaje en un terreno específico. En este sentido, los marcos son susceptibles de ser burlados, subvertidos y modificados. No obstante, ¿qué efectos tienen estos modos de aprehensión en la agencia y la disposición afectiva de los sujetos?

Butler afirma que toda vida es precaria y vulnerable, en tanto que somos seres humanos expuestos a la amenaza y a la violencia; por esta razón, somos seres interdependientes que necesitamos de cuidado. La vulnerabilidad envuelve las relaciones que establecen los individuos entre sí, pero, según sean las condiciones institucionales que median tales relaciones, estas pueden llegar a maximizar o minimizar la condición de precariedad. La precariedad tiene que ver con aquellas condiciones que afectan a la vida y que hacen sentir que la existencia se constituye en relación con los otros; en últimas, considerar que el cuerpo es una entidad circunscrita: "el sujeto que soy está ligado al sujeto que no soy, que cada uno de nosotros tiene el poder de destruir y ser destruido y que todos estamos ligados los unos a los otros por este poder y esta precariedad" (Butler, 2010:71). Por lo tanto, por medio de las condiciones en las que se da tal interdependencia, se establece qué vidas son más precarias que otras. En este sentido, los cuerpos, al estar entregados a normas e instituciones, pueden llegar a maximizar o minimizar su precariedad.

La mirada que hace Butler del cuerpo no es ajena al pensamiento de Baruch Spinoza, quien considera que el cuerpo posee un conatus o una potencia implícita que lo incita a perseverar en su ser; sin embargo, esa potencia puede aumentar o disminuir, según las fuerzas sociales a las que se ve expuesto el cuerpo, pues estas generan condiciones que permiten o no que el cuerpo persista y prospere. Un sujeto puede disminuir su capacidad para vivir y actuar si está más expuesto a una violencia arbitraria que otros. Por ejemplo, algunas personas que pertenecen a la comunidad LGBTI pueden asociar la aversión y el rechazo que experimentan en su cotidianidad con sentimientos de vergüenza y auto rechazo, que afectan directamente su agencia. La performatividad de los afectos consiste, entonces, en la configuración afectiva que se da a partir de los marcos de inteligibilidad que mantienen y reproducen formas de percibir el encuentro con los otros, en especial con la diferencia, en tanto que los afectos dan cuenta de cómo me conciben los otros y cómo me concibo a mí mismo. Así, depende del contexto y la cultura a la que pertenezcan los individuos, se da mayor o menor proclividad a ciertos afectos. También, esta performatividad afectiva refiere a la potencia que poseen los seres humanos para subvertir tal configuración por medio del afecto que surge desde la resistencia, más fuerte.

Performatividad y afectos,

Luz Helena Di Giorgi-Fonseca- p. 107-132 
Entonces, ¿de qué manera la disposición afectiva es manipulada?, ¿qué papel desempeña el repudio en la consideración en contextos de opresión y exclusión?, ¿qué papel juega el afecto que subvierte la configuración identitaria normativa? Con el fin de estudiar esas cuestiones, en la segunda parte se realizará un análisis acerca de las formas contemporáneas de la opresión y exclusión en sociedades liberales. En este caso se trae a colación las indicaciones que hace Iris Marion Young en su texto La justicia y la política de diferencia, ya que allí revela que la configuración de las nuevas formas de opresión no se ejercen por un poder tiránico, sino que se dan a través de prácticas cotidianas más o menos inconscientes que se expresan en el trato afectivo con los otros.

\section{AFECTOS Y MECANISMos de distribución AFECTIVA}

En la propuesta de Butler, el tema de la disposición afectiva aparece en tres momentos: 1) En Mecanismos psíquicos de poder, la autora intenta explicar la relación apasionada que tiene el sujeto con la ley en los procesos de identificación. 2) En Vida precaria y Marcos de guerra, en el cual analiza la distribución diferencial del duelo establecido por los marcos de inteligibilidad en contextos de exclusión. 3) En las consideraciones que hace Butler en Marcos de guerra acerca de la experiencia afectiva como posibilidad para la crítica y la agencia.

$\operatorname{Los}_{\text {afectos }}{ }^{9}$ no provienen, del todo, de una experiencia privada ni espontánea.

\footnotetext{
9 Uno de los aspectos que se deben tener en cuenta tiene que ver con lo que se entiende por emoción y las semejanzas o diferencias que posee con las categorías con las que usualmente se le relaciona: sensación, pasión o sentimiento. Se puede decir que la diferencia entre ellas se refiere más a una distinción analítica e histórica, que a un aspecto radical que esencialmente las diferencie. Histórica, en el sentido de que cada una de estas nociones ha sido usada para explicar lo que sucede de manera transversal en la mente y el cuerpo; no obstante, bajo modelos de pensamiento distintos que han provenido de la filosofía, la antropología y la sociología. A través de estos puntos de vista, se busca comprender la experiencia corporal, ya sea desde una división entre alma y cuerpo o, por el contrario, una visión que los evidencie como expresiones de una misma cosa. La palabra pasión se asociaba con el término latino pathé, que se traduce literalmente como pasión, sufrimiento o perturbación. Por ejemplo, para Platón, bajo una mirada rápida, las pasiones hacen parte del alma que debía ser armonizada; mientras, para Aristóteles, por lo menos en la Retórica, tienen un carácter cognitivo y cumplen una función importante de persuasión. Según Susan James (1997), durante el siglo XVII, se convierten en un requisito fundamental para comprender el comportamiento de los seres humanos, en especial, para entender la manera cómo se debe ejercer control sobre sí mismos y sobre los otros. René Descartes hace una descripción fisiológica de las pasiones, en la que asegura que estas refieren a un estado particular del cuerpo que puede ser controlado por la razón; por el contrario, para Baruch Spinoza las pasiones son afectos que responden a la manera como el cuerpo ha sido afectado, pero que no difieren del pensamiento, para él las pasiones son importantes porque permiten o no que un individuo actúe. Por otro lado, la palabra sentimiento en la época moderna se enfatiza en el sentido moral de las pasiones, que inicia en el siglo Xviı; así lo analiza Julio Seoane en Del sentido moral a
} 
Generalmente, se les considera como si fueran anteriores a la labor de comprender e interpretar; sin embargo, Butler considera que esta idea es errónea, ya que los afectos dependen, en parte, de las condiciones sociales y los regímenes de poder que disponen al sujeto a una respuesta perceptiva y afectiva determinada. Los afectos, bajo esta perspectiva, son capacidades perceptivas que cumplen un papel fundamental a la hora de comprender, por ejemplo, la manera como las personas reaccionan ante una situación indignante o de duelo.

De alguna manera, los afectos revelan la forma como las personas reaccionan frente a las relaciones que mantienen con los otros. Estas reacciones no sobrevienen de una forma espontánea, sino que también son aprehendidas en un contexto en el que estas se configuran a partir de una serie de símbolos u $\operatorname{artefactos}^{10}$, que influyen en la constitución del modo de ser de los individuos y en la forma como van a percibir a los otros. Butler considera que el encuentro afectivo puede considerarse como una experiencia inicial que no necesariamente está mediada por una determinación social; sin embargo, "(...) depende de apoyos sociales para sentir: llegamos a sentir sólo con relación a una pérdida percibible, la cual depende de estructuras de percepción sociales; y solo podemos sentir afecto, y reivindicarlo como propio, a condición de estar ya inscritos en un circuito de afecto social" (Butler, 2010:80).

En este punto, quisiera ampliar la consideración de los afectos, a partir de lo que dice Sara Ahmed en The cultural politics of emotion, pues ella afirma que las emociones dan sentido y forma a las relaciones, al respecto afirma:

\footnotetext{
la moral sentimental, libro en el que asegura que la evaluación racional de la pasión comienza a tener un papel importante en la experiencia de la intimidad. Una visión fisiológica de las emociones se establece con William James (1884), quien considera que las emociones son irracionales y refieren a aquellas respuestas que tiene el cuerpo frente a la realidad y las experiencias. Finalmente, desde los años setenta, la categoría de emoción, por lo menos desde la antropología y la sociología, es considerada como un elemento cognitivo, simbólico y cultural que permite comprender tanto la acción humana como las relaciones sociales. En términos generales, eso que podemos llamar, por ahora, de un modo amplio como una experiencia humana finita, ha tenido tres momentos importantes de interpretación: el primero tiene que ver con la consideración de tal experiencia como una pasión del cuerpo; un segundo momento, en el que la emoción es relacionada con un carácter cognitivo; finalmente, las emociones son consideradas formas de inteligencia. Estas tres posiciones se encuentran atravesadas por las distintas representaciones que han realizado los saberes y disciplinas de cada época. Es importante advertir que a lo largo del texto se van a manejar indistintamente las nociones de afecto y emoción.

${ }^{10}$ Al respecto, ver el análisis que realiza Elaine Scarry (1985) en su texto The body in pain, en el cual la autora muestra la manera como el dolor físico es controlado por medio de la retórica estatal. Especialmente, en el segundo capítulo de este texto, la autora asegura que, al contrario de otros estados como el hambre, el deseo, el miedo u otros que se encuentran determinados por un objeto externo, el dolor depende de artefactos imaginarios.
}

Performatividad y afectos,

Luz Helena Di Giorgi-Fonseca- p. 107-132 
(...) Las emociones le dan forma a la superficie de los cuerpos, formación que deviene a partir de acciones repetitivas que se dan en el tiempo, así como acercamiento o distancia con los otros. De hecho la atención a las emociones podría mostrarnos que nuestras acciones son reacciones, en la medida en que somos formados en el encuentro con los otros ${ }^{11}$.

Esta perspectiva sugiere que, en el encuentro con los otros deviene una serie de afectos que circulan y tienen eficacia. La capacidad afectiva, en este sentido, es una experiencia colectiva, en tanto que los individuos estamos vinculados a estructuras sociales comunes. Es decir, que un individuo está más dispuesto a ciertas reacciones afectivas específicas, pues las considera apropiadas y legítimas, mientras que otras quedan rezagadas y quizás censuradas; por ejemplo, cuando la distribución diferencial de la precariedad y del duelo responden a fines políticos, los marcos culturales orientan la disposición afectiva e indican qué vidas deben ser lloradas y cuáles ni siquiera pueden contar como vidas.

En Marcos de Guerra, Butler describe el caso de la autoprotección soberana que constituye al sujeto americano, quien se configura blindado frente aquellos que considera como un riesgo. En lugares donde se exalta el fervor nacionalista y se constituye un sujeto homogeneizado, la diferencia es una amenaza o un riesgo para la nación. El sujeto nacional en nombre de la soberanía es capaz de "defender una frontera en un caso y violarla en otro con total impunidad" (Butler, 2010:77). Bajo esta perspectiva, y como lo considera Laurent Berlant (2011) en su análisis a la cultura estadounidense, el sentimentalismo nacional responde a una promesa de una imagen de nación, bajo la que se reproduce una serie de emociones con la finalidad de impulsar creencias y falsear otras; en últimas, para conformar la pertenencia a una identidad. Berlant (2011) afirma que el sentimentalismo nacional se constituye en el momento en el que se politiza una serie de afectos, en los que la ciudadanía, reconocida y realizada, ve a las personas que sufren como el ejemplo de una ciudadanía fallida. En este sentido, y de la misma manera como lo va a considerar Butler, la cuestión política se entromete en el establecimiento de la distribución diferencial del duelo, en la que se piensa que ciertas vidas son más justificables que otras “(...) son capaces de convertir la

\footnotetext{
11 "(...) Emotions shape the very surfaces of bodies, which take shape though the repetition of actions over time, as well as through orientations towards and away from others. Indeed, attending to emotions might show us show all actions are reactions, in the sense that what we do shaped by the contact we have with others" (Ahmed, 2014: 4) La traducción es de la autora.
} 
propia destructividad del sujeto en algo justificable y su propia destructibilidad en algo impensable" (Butler, 2010:76).

En contextos en los que la capacidad perceptiva se encuentra determinada por una lógica diferencial de duelo, la disposición afectiva de los sujetos se expresa homogénea y compartida. Por esta razón, los individuos estarán más dispuestos a ciertos afectos que a otros. En situaciones de guerra, por ejemplo, ciertas experiencia de dolor son más reconocidas y amplificadas que otras, en tanto que se devela qué personas pertenecen al nosotros y por lo tanto se estable qué vidas, por ser más valiosas, deben ser lloradas y qué vidas no: "En las guerras contemporáneas en las que los Estados Unidos está directamente involucrado, como las de Irak y Afganistán, podemos ver cómo se regula el afecto para apoyar tanto el esfuerzo bélico como, más concretamente, la pertenencia nacionalista" (Butler, 2010:66).

Butler (2010) hace referencia al antropólogo Talal Asad, quién intenta dar una explicación respecto al proceder de la manipulación afectiva en su obra Sobre el terrorismo suicida. Él se pregunta, ¿por qué sentimos horror y repulsa, por ejemplo, por un atentado suicida y no por la violencia patrocinada por el Estado? Una de las respuestas que ofrece es que las reacciones morales, como la indignación que toma la forma de afecto, responden a marcos de interpretación de los cuales no conocemos realmente su estructura y eficacia. Es importante recalcar en este punto el papel de la política en la determinación de las reacciones afectivas, en tanto que: a) determina qué vidas deben ser consideradas y dignas de duelo; b) tiene en cuenta las indicaciones de Berlant en la reproducción retórica de un dolor traumático, en contraste con la establecimiento del bienestar de la ciudadanía nacional realizada; c) influye en las prácticas cotidianas como a continuación se analizará.

En contextos liberales, en los que hay compromisos con la igualdad y existe un reconocimiento explícito a la diferencia, es paradójico que se presente una distribución exclusiva del duelo y una reproducción de repudio a ciertos grupos sociales. Por esta razón, cabe preguntarse por la estructura y eficacia de la manera como opera tal situación a partir de la manipulación afectiva o la politización del sentimiento. Para explicar esta paradoja, se recurre a Iris Marion Young, pues sus planteamientos permiten comprender cómo desde las prácticas sociales se expresa la performatividad afectiva que establece Butler. Es importante aclarar que Young no hace referencia explícita al concepto de performatividad, sino que intenta analizar la manera como las personas 
experimentan situaciones de discriminación y opresión ${ }^{12}$ en la interacción cotidiana, no por un poder tiránico, sino por prácticas inconscientes de una bien intencionada sociedad liberal, que se encuentran estructuradas por una serie de las instituciones sociales, políticas y económicas más importantes de la sociedad. El énfasis de ella se establece en cómo dichas instituciones afectan de forma diferenciada a los grupos sociales.

Una de las inquietudes que aborda Young tiene que ver con la comprensión de las nuevas formas de exclusión que, en su mayoría, aparecen en contextos en los que la igualdad formal es aceptada por todos pero en los que, paradójicamente, a nivel corporal y afectivo existen prácticas de discriminación y opresión. Desde el punto de vista normativo y estructural, en sociedades liberales-capitalistas, la opresión es experimentada por grupos sociales ${ }^{13}$ que denuncian explotación, división del trabajo y marginación. Sin embargo, en situaciones en las que hay imperialismo cultural y violencia sistemática arbitraria, se presentan interacciones cotidianas inconscientes que hacen que los grupos sociales, considerados como la diferencia, se invisibilicen a través de prácticas que no se cuestionan, pero que son eficaces a la hora de ejercer discriminación y opresión ${ }^{14}$.

\footnotetext{
${ }^{12}$ Hay que advertir que Young elabora una forma nueva de concebir la opresión, pues la entiende como: "las desventajas e injusticias que sufre alguna gente no por un poder tiránico que la coaccione, sino por prácticas cotidianas de la bien intencionada sociedad liberal" (Young 2000:74). En este sentido, la opresión es estructural, es decir, que las causas de la misma refieren a la aplicación de normas, reglas institucionales, hábitos y símbolos que no se cuestionan.

${ }^{13}$ Los grupos sociales tal y como los define Young (2000) son "(...) un colectivo de personas que se diferencia al menos otro grupo a través de formas culturales, prácticas o modos de vida. Los miembros de un grupo tienen afinidades específicas debido a sus experiencias o forma de vida similares, lo cual lleva a asociarse entre sí más que con otras personas que no se identifican con el grupo o que lo hacen de otro modo" (77). Bajo esta perspectiva, un grupo social se caracteriza por los siguientes aspectos: a) Los miembros que pertenecen a un grupo social pueden llegar a poseer una misma identidad, modos de vida parecidos, experiencias comunes. b) Las personas se reconocen como miembros de un grupo social en la medida en que este se encuentra con otras colectividades y reconocen sus diferencias. Hay que advertir que, no solo en el encuentro con las diferencias las personas pueden identificase como miembros de un grupo social, esta identificación puede surgir por procesos sociales, es decir, por las condiciones institucionales que fortalecen la división sexual del trabajo: "Los procesos sociales también diferencian a los grupos dentro de una misma sociedad. La división sexual del trabajo, por ejemplo, ha creado grupos sociales de mujeres y hombres en todas las sociedades conocidas". En este sentido, las propias instituciones sociales, económicas y culturales contribuyen en la constitución de nuevos grupos sociales, como sucede con la división del trabajo en la que se crean, por ejemplo, cierto tipo de roles para el género. c) Las personas no deciden voluntariamente pertenecer al grupo social con el que se identifican.

${ }^{14}$ Las formas de opresión que explica Young (2000) en su texto son las siguientes: explotación, que consiste, no en la desigualdad de la distribución de la riqueza, sino en la desigualdad en el aprovechamiento de los beneficios del trabajo; la marginación, refiere a las personas que el sistema capitalista desecha, porque las considera como no útiles; la carencia de poder alude a las personas que
} 
Entre estas prácticas cotidianas, se encuentran la reproducción de representaciones sociales que tienen como fin estigmatizar a los individuos; asimismo, se involucran ciertas reacciones corporales como gestos, tonos de voz, actos de atracción y aversión que definen sus cuerpos como feos, temidos, odiosos, no dignos de reconocimiento, ni duelo. Para desarrollar este punto, Young recurre a los tres niveles de subjetivación elaborados por Anthony Giddens, en su texto La constitución de la sociedad, pues, a partir de estos planteamientos, explica cómo las situaciones de opresión se establecen en conductas habituales no cuestionadas.

Giddens (1995) afirma que los procesos de subjetivación implican tres niveles: la conciencia discursiva, la conciencia práctica y el sistema básico de seguridad. Estos tres estadios explican la manera como los sujetos constituyen su agencia en relación con la estructura social, que de alguna manera los determina. La conciencia discursiva hace referencia a aquellas ideas que se expresan verbalmente y que se enuncian en reglas y normas explícitas. La conciencia práctica, por su parte, tiene que ver con el modo como los sujetos utilizan las reglas, en este caso, se relaciona con el comportamiento tácito que legitima la interacción cotidiana de los sujetos, sin ser parte de la expresión discursiva explícita. El sistema de seguridad se refiere a la protección ontológica del sujeto, que exigen los procesos de identificación para el desarrollo de la autonomía en el contexto social.

Hay que advertir que para Giddens existe una relación entre la conciencia discursiva y la conciencia práctica; sin embargo, no deja de presentarse en la práctica diaria una diferencia entre lo que se dice y lo que se hace. $\mathrm{Al}$ respecto, afirma Young:

(...) la conciencia discursiva afirma que la gente negra, las mujeres, las personas homosexuales y las discapacitadas son como yo. Pero en el nivel de la conciencia práctica ellas están afectivamente marcadas como diferentes. En esta situación, las personas de los grupos despreciados amenazan con atravesar la frontera de la identidad del sujeto porque la conciencia discursiva no los señalará como completamente diferentes (Young 2000:246).

pierden su autonomía y a la imposibilidad de desarrollar capacidades, debido a su etnia, clase social, color de piel, etcétera; imperialismo cultural tiene que ver con el modo como los rasgos dominantes de una cultura invisibilizan otras formas de vida; y la violencia hace referencia a la constante amenaza en la que viven los grupos sociales en razón de su identidad.

Performatividad y afectos,

Luz Helena Di Giorgi-Fonseca- p. 107-132 
Young muestra cómo en los encuentros cotidianos algunas personas suelen comportarse de una forma especial frente a otras que pertenecen a ciertos grupos sociales. Por ejemplo, ciertas personas pertenecientes a un grupo social privilegiado ${ }^{15}$ a menudo pueden expresar nerviosismo y evitan el contacto visual al interactuar con un grupo que consideran de menor estatus. En sociedades democráticas, desde un punto de vista racional, la igualdad formal es un discurso que la mayoría de las personas acepta, proclama y defiende; pero, en el momento en que alguien critica ciertas actitudes discriminatorias - como las indicadas, o censura un estereotipo, o chiste sexista-, tal situación se tiende a minimizar o a tildar como exagerada.

Estas formas de opresión se presentan a través de prácticas inconscientes que se manifiestan en las reacciones corporales: "afectos", imágenes y actitudes que hasta el momento se han ignorado. Young revela cómo en los encuentros cotidianos, un grupo dominante, ante la presencia de la diferencia, reacciona de forma especial, expresa nerviosismo o aversión en tanto que percibe una amenaza ontológica a su subjetividad:

En la interacción social el grupo social superior a menudo evita estar cerca del grupo de menor estatus, evita el contacto con la mirada, no mantienen su cuerpo en una actitud abierta. Un hombre negro camina por la habitación grande en una convención de negocios y nota que el nivel de ruido disminuye, no completamente, pero decididamente disminuye (Young, 2000:225).

Según Young, los teóricos de la justicia social se han preocupado por las condiciones de la distribución de los bienes sociales, pero no tienen en su consideración los comportamientos, ni los afectos que se presentan en la conciencia práctica y que se transmiten en las prácticas cotidianas inconscientes de la bien intencionada sociedad liberal. Esta situación es ejemplificada en la novela Americanah, de la escritora nigeriana Chimamada Ngozi Adiche, en la que cuenta las experiencias que vive una joven proveniente de Lagos, en los Estados Unidos. Una de las situaciones paradójicas que desarrolla en la novela, tiene que ver con las distintas reacciones que genera la designación de una persona como "mestiza". Mientras para la gente en Nigeria era digno de admiración que denominaran así a las personas, en los Estados Unidos era fuente de repulsa y ofensa.

\footnotetext{
${ }^{15}$ Grupo que por ser dominante no percibe la existencia de su propio grupo, ya que ocupa una posición neutral y universal.
} 
Entre las distintas experiencias que manifiesta la autora, resalta aquella en la que describe las reacciones inconscientes que manifiestan los norteamericanos al compartir con una joven nigeriana, con estudios y ciertos privilegios sociales; para los estadounidenses es sorprendente que una chica que proviene de estos lugares tenga unos intereses y unas capacidades iguales a las que desarrolla un chico en el primer mundo.

Esta situación tiene como consecuencia la configuración de dos formas particulares de subjetividad. Por un lado, la de los grupos privilegiados que experimentan, dice Young, un sentimiento de ansiedad de frontera o límite, a nivel de la conciencia práctica, pues en la medida en que los grupos privilegiados perciben que cada vez más se han desdibujado los criterios que establecen las diferencias concretas entre los grupos sociales, la única posibilidad que les queda es generar la distinción a partir de la repugnancia irracional; si todos somos iguales, "cualquiera puede transformarse en gay, especialmente yo; por lo tanto, la única manera de defender mi identidad es darme la vuelta con una repugnancia irracional" (Young, 2000:246). Por el otro, la subjetividad de los grupos minoritarios, estereotipados como seres abyectos, que experimentan temor y desvalorización de sí mismos ${ }^{16}$.

Un ejemplo que condensa estas reflexiones teóricas es descrito por el psicoanalista colombiano Mario Bernardo Figueroa en uno de sus artículos escritos para Razón Pública, el cual se titula “... ni con el pétalo de una rosa”.

\footnotetext{
${ }^{16}$ Nussbaum, en El ocultamiento de lo humano, hace un seguimiento histórico a la situación normativa que ha tenido la repugnancia y la vergüenza en sociedades liberales, en especial, la estadounidense. El criterio de la vergüenza, por ejemplo, se relaciona con los siguientes criterios normativos: en primer lugar, con la humillación y el bochorno, que generalmente están relacionados con las nociones sociales del estigma. La humillación se entiende como el perjuicio o el daño que experimenta una persona y que atenta contra su dignidad. Imaginarios sociales como lo "normal" juegan un rol importante en este punto; así lo asegura Nussbaum: “(...) lo normal es lo usual, lo que la mayoría de las personas es o hace. Lo opuesto a lo "normal", es ese sentido, es lo 'inusual'. Por otro lado, tenemos la noción de lo bueno o normativo: lo normal es lo correcto. Lo opuesto a lo 'normal', en este sentido, es 'inapropiado', 'malo', 'deshonroso' (Nussbaum 2012:255). Bajo esta categoría, se hace una clasificación de los individuos, de aquellos que entran dentro de la categoría de lo "normal" y aquellos que no encajan en esa noción y se le estigmatiza. Uno de los aspectos que agrega la autora es que la idea de lo normal es tan relevante en las sociedades porque en cierta medida sirve para ocultar nuestra finitud. Ella dice que la idea de normalidad generalmente se basa en imaginarios que quieren ocultar nuestra humanidad, mortalidad, finitud, nuestra corporeidad: "Los normales saben que sus intelectos son defectuosos en muchos sentidos; todos los seres humanos poseen numerosas deficiencias en el conocimiento, el juicio y la compasión. Pero con los discapacitados mentales en torno de ellos y estigmatizados como 'imbéciles', 'idiotas', 'idiotas mongoloides' o 'gente loca', los normales se sienten sabios y brillantes” (Nussbaum 2012:256-257).
}

Performatividad y afectos,

Luz Helena Di Giorgi-Fonseca- p. 107-132 
Allí analiza el incremento paradójico de la violencia hacia las mujeres en sociedades en las que, cada vez más, a nivel discursivo, no hay razón que justifique su agresión. Él se percata de que en los contextos en los que más se exaltan representaciones que expresan el ideal de una mujer perfecta y sagrada, más se les odia y son víctimas de agresión (Figueroa, 2011). Si bien existen varias

causas que generan este tipo de violencia, el autor analiza el papel que desempeña la consideración sagrada de lo femenino en el contexto colombiano, como representación ficticia que se reproduce en la conciencia práctica, en la imagen que se transmite en el adagio popular que dice: "a las mujeres no se les toca ni con el pétalo de una rosa". Esta sentencia cursi, dice, proviene del amor cortés que configura un "ideal de mujer", que ha de ser exaltada como objeto de adoración. Considerar que a las mujeres no se les toca con el pétalo de una rosa conlleva implícita la idea de que las mujeres deben ser objeto de adoración y puestas en un lugar sagrado. A nivel de la consciencia práctica, con esta representación ficticia, se empieza a clasificar a las mujeres entre aquellas que hacen el mérito por conservar ese carácter virginal, que implica lo sagrado - es decir, las que no se dejan tocar-, y otras, que han de ser repudiadas por el hecho de ser tocadas. Figueroa continúa registrando en su artículo cómo, en contextos de guerra, por ejemplo, las mujeres se convierten en botín de guerra, dado que, antes de despojar al enemigo de sus bienes, lo que se ataca es lo sagrado. Este caso nos muestra cómo las imágenes ficticias, que refieren a las mujeres, se encuentran acompañadas de un afecto que en la conciencia práctica se reproduce y no se cuestiona, sino que, por el contrario, en nuestro contexto, se acoge como motivo de reivindicación.

Si bien la disposición afectiva es manipulada a través de los marcos de inteligibilidad y trasmitida por medio de la legitimidad de una serie de discursos que paradójicamente promulgan la igualdad, las formas de percepción manifiestan otra cara de la moneda, en tanto que exponen situaciones de opresión y discriminación, que se expresan a través de prácticas inconscientes. Por tanto, una de las preguntas que se puede formular es acerca del papel de la agencia o de la capacidad de acción que tienen los sujetos en nuestro contexto político: ¿En qué radica su agencia, si los afectos o la capacidad perceptiva, en parte, no se escapan de su determinación? 


\section{Crítica, AgENCIA Y ONTOLOGÍA SOCIAL}

(...) Cada uno de nosotros se constituye políticamente en virtud de la vulnerabilidad social de nuestros cuerpos — como lugar de deseo de vulnerabilidad física, como lugar público de afirmación y exposición-. La pérdida y la vulnerabilidad parecen ser la consecuencia de nuestros cuerpos socialmente constituidos, sujetos a otros, amenazados por la pérdida, expuestos a otros y susceptibles de violencia

(Butler, 2006:46).

En los planteamientos de Butler aparece un aspecto fundamental, que tiene que ver con la manera como se establecen los procesos de subjetivación, ya que esta puede ser problemática, debido a que puede llevar consigo una serie de representaciones sociales que reproducen situaciones de discriminación y opresión. En este caso, la subjetividad es construida desde instancias dominantes que no tienen en cuenta los individuos a los que dicen referirse, como bien se señaló en la primera parte. En Mecanismos psíquicos del poder, la autora afirma que el sujeto está vinculado apasionadamente con la ley, gracias a que la norma, además de determinar el comportamiento, constituye al sujeto, pues configura las condiciones que hacen que su vida sea posible. Por esta razón, los afectos que experimentan los individuos son el elemento que conecta la norma y la corporalidad. En este sentido, es inevitable desear lo que me hace inteligible para la comunidad; al respecto, afirma Butler: "Desear las condiciones de la propia subordinación es entonces un requisito para persistir como uno/a mismo/a (...)" (Butler, 1997:20). A pesar de que la constitución del sujeto se debe a un efecto del poder dado por los marcos de inteligibilidad, Butler reconoce que el sujeto ejerce un nivel de agencia ${ }^{17}$, en tanto que este es también potencia. La agencia performativa, por lo menos, radicaría no solo en reivindicar intereses políticos, sino en cuestionar las posiciones identitarias.

\footnotetext{
${ }^{17}$ Para ampliar la noción de agencia, ver la definición que hace Wiliam Sewell (2006). En uno de sus artículos, "Una teoría de la estructura: Dualidad, agencia y transformación", afirma que la agencia tiene que ver con: “(...) la habilidad de transformar en cierto grado esas relaciones sociales. Como lo veo, los agentes están dotados, por las estructuras, de poder para actuar con y contra otros; tienen conocimiento de los esquemas que contiene la vida social y también acceso en alguna medida a los recursos, tanto humano como no humanos. La agencia surge del conocimiento que de los esquema poseen los actores, lo cual significa la habilidad de aplicarlos a nuevos contextos" (p. 165). De alguna manera, la agencia o ese poder actuar depende de la habilidad interpretativa que tiene el sujeto de los distintos saberes que lo atraviesan y lo materializan. Tales interpretaciones manifiestan la manera como los sujetos enfrentan y adoptan las normas sociales a su cotidianidad. Ser agente significa, entonces, tener algún grado de control de las reglas y recursos que se transponen y reproducen en las relaciones sociales.
}

Performatividad y afectos, 
El sujeto se forma a partir de la conciencia que, como mecanismo psíquico, es el lugar en el que se reiteran las normas pero, paradójicamente, también se transforman. Según Butler, la sujeción es una condición para la subordinación, pero también una condición para la agencia: "creo que la performatividad política surge de otra noción de la vida corporal, una vida que es vulnerable, interdependiente, pero también agencial" (Entrevista con Judith Butler. Soley-Beltran y Sabsay, 2012:223). Esta consideración permite pensar en las posibles caras de la agencia política: la subversión y la resistencia, por medio de una coalición entre individuos que se articulan para reivindicar la diferencia por medio de su persistencia corporal. Butler no subestima la capacidad que tienen los seres humanos de reinterpretar las normas, de hecho, se podría decir que la continuidad de ciertos esquemas depende de esa reinterpretación, que hace parte de una habilidad inherente a los seres humanos. Hay que advertir que las reinterpretaciones son diversas, debido al contexto y a las posiciones sociales — género, raza, riqueza, ocupación, conocimiento, etcétera- en las que se encuentran los individuos.

Para Butler, pensar en otras formas de reconocimiento por fuera del Estado se convierte en un deber, pues desde este ámbito fácilmente puede imponerse un discurso paternalista, que puede llegar a invisivilizar reivindicaciones hechas desde la esfera pública a través de coaliciones plurales, que buscan otros vehículos de legitimación como la exposición de la vulnerabilidad. Esto sucede, por ejemplo, en casos en los que las políticas abanderadas por el discurso de los derechos humanos refuerzan la vulnerabilidad en lugar de modificar las condiciones que la generan. Lo más interesante del planteamiento de Butler es que ofrece la posibilidad de pensar en acciones que no nacen necesariamente desde la autoridad legítima del Estado, sino de expresiones que ponen en tensión las estructuras identitarias que se configuran desde esta fuente de poder legitimadora. Desde el punto de vista de la autora, el cuerpo afectado que se moviliza expresa afectos que "(...) devienen no sólo en la base, sino también en la materia de ideación y crítica" (Butler 2010:59).

Preguntar y analizar las imágenes ficticias, fantasías inofensivas, junto con los afectos que las intensifican como el odio y aversión, permitiría pensar en las condiciones frente a las que se aprehende la precariedad de la vida y, por tanto, luchar contra el afecto dominante y regulador. Aquí, la tarea que nos propone Butler es pensar en modos o formas interpretativas que permitan la modificación del afecto. Los afectos, en este sentido, son una reacción interpretativa, condicionada por unos marcos de interpretación, que se puede revertir por medio de otras expresiones, como las narraciones y las imágenes, 
que le hagan contrapeso a las ficciones que inconscientemente reproducen discriminación y opresión. Al respecto, afirma Butler: "como tales respuestas afectivas están invariablemente medidas, apelan a y realizan ciertos marcos interpretativos; también pueden cuestionar el carácter supuesto de estos marcos y de esa manera suministrar condiciones afectivas para la crítica social" (2010:59). Bajo esta perspectiva, es a partir del afecto como se comienza a ejercer una crítica de los discursos racionales que generan exclusión.

Para seguir a Spinoza, la manera como pueden modificarse los afectos que son condicionados por los marcos de inteligibilidad diferencial puede ser a partir de la generación de una experiencia afectiva más fuerte. Spinoza afirma en la Ética que un afecto solo puede ser modificado por otro afecto "un afecto no puede ser reprimido ni suprimido sino por un afecto contrario y más fuerte que el afecto a reprimir" (p. 7). En este sentido, no podemos modificar las imágenes y los esquemas fácilmente, debido a que estas atraviesan los cuerpos; se debe pensar en mecanismos y expresiones que de alguna manera logren hacerle frente a los afectos dominantes. Lo normativo, tal y como lo considera Butler, nunca se constituye de un modo definitivo; es decir, que la vida —en algún momento- excede las determinaciones a las que se ve expuesta. Por esta razón, es desde el cuerpo, especialmente desde la experiencia afectiva, que se pueden plantear críticas y nuevas formas de aprehensión perceptivas de los otros.

Butler hace evidente cómo las normas del género, por ejemplo, nos preceden y actúan sobre nosotros, en la medida en que nos obligan o nos interpelan de tal manera que hacen que estemos obligados a reproducirlas. Sin embargo, debido a que esta operación no es mecánica, sino que es un proceso en el cual el cuerpo se ve afectado, tal afección puede, de forma inesperada, responder de una forma distinta a la normalización, a saber, subvertir, desviar la norma. En ese sentido, el cuerpo, según se vea afectado, logra romper con los criterios mecánicos de la repetición, razón por la cual una de las tareas que propone Butler tiene que ver con enfocar la mirada en el modo como nos afecta del discurso.

A modo de ejemplo, en Marcos de Guerra, la autora muestra cómo los poemas escritos por los detenidos de la prisión de Guantánamo ${ }^{18}$, a rasguños

\footnotetext{
${ }^{18}$ Los poemas de Guantánamo, escritos por internos, son una recopilación hecha por un abogado de los EE. UU., que es calificada por el pentágono como peligrosa para la seguridad nacional; así lo indica la editorial del diario El País Internacional (21 de junio de 2007). Ver también: Falkooff, M. (2008). Poemas de Guantánamo. Madrid: Península.
} 
en vasos de poliespán, develan las experiencias vividas por ellos en el cautiverio. Estos poemas, que sobrevivieron a la censura del departamento de defensa norteamericano, según Butler, demuestran el valor de la resistencia y la posibilidad de sobrevivir a las condiciones de guerra. Los poemas fueron censurados, debido a que, según las autoridades estadounidenses, representaban un riesgo para la seguridad nacional por "su contenido y formato". No obstante, Butler se pregunta, "¿cómo pueden la sintaxis o la forma de un poema ser percibidas como una amenaza para la seguridad de la nación?" (Butler, 2010:86) ¿Qué es lo que tiene la poesía? Ella afirma que los afectos que se trasmiten a través de los poemas permiten desviar la trayectoria del afecto condicionado; en este sentido, ponen en cuestión los afectos seleccionados reproducidos por el Estado nación, ya que evidencian que en este contexto algunas vidas no cuentan para ese ideal nacional, ni para el discurso de los derechos humanos. Lo anterior ocurre porque, a través de dichos textos, los poetas se preguntan "¿cómo puede un cuerpo torturado formar palabras?", “¿cómo es posible, la tortura, en nombre de la paz?” (Butler, 2010:87-89). A partir de esta manifestación, "(...) podemos preguntarnos qué afecto es vehiculado verbalmente por estos poemas y qué serie de interpretaciones vehiculan en forma de afectos, incluidas la añoranza y la rabia" (Butler, 2010:90).

Butler propone pensar en una nueva ontología social que considere la precariedad y la interdependencia a la cual se ve implicado el cuerpo. Por esta razón, envuelve dos presupuestos importantes: por un lado, pensar en la precariedad de la vida implica reconocer que el cuerpo tiende a perseverar en su ser; por el otro, que tal situación debe pensarse en un contexto relacional, en tanto que el cuerpo convive con otros cuerpos. Esto se hace evidente, como se había indicado más arriba, en el hecho de que la autora acoge el presupuesto del conatus spinocista, que establece que el cuerpo posee una potencia implícita que lo incita a perseverar en su ser. Así los cuerpos determinados por marcos normativos pueden llegar a maximizar o minimizar la precariedad, en tanto que son condiciones que permiten o no que el cuerpo persista y prospere.

En uno de sus últimos ensayos, recopilado en un texto publicado recientemente, Senses of the Subject, la autora hace una reflexión al conatus spinocista y, especialmente, pone atención a una de las proposiciones más importantes que el autor defiende en uno de sus textos, Ética demostrada según el orden geométrico, en el cual afirma: "El conato con el que cada cosa se esfuerza en perseverar en su ser, no es nada más que la esencia actual de la 
misma" (Spinoza:7). De alguna manera, la propuesta de Butler se enmarca en un dilema que no es ajeno al pensamiento del filósofo holandés, el cuestionamiento acerca del deseo de vivir. La consideración de esta premisa tiene como consecuencia la aceptación de que la mayoría de modos de ser, que hacen parte de este mundo, desean persistir en su existencia; eso quiere decir que, por lo menos, en su constitución no albergan algún elemento que los lleve a una autodestrucción ${ }^{19}$. Sin embargo, si este aspecto hace parte de la condición humana, ¿de qué manera este presupuesto es compatible con la nueva ontología social que propone Butler?

Las inquietudes que aborda Butler respecto al conatus tienen que ver con: ¿qué se conserva?, ¿cómo se conserva? Al interpretar a Spinoza, ella afirma que no se debe reducir ese deseo de vivir a un interés de autoconservación, pues la conservación no se reduce a un deseo individual de querer sobrevivir, sino que ese deseo, en la propuesta del filósofo, significa perseverar en relación con los otros. Perseverar no es una situación exclusivamente autorreferencial, sino que implica todo un reconocimiento del mundo exterior, en tanto que este se convierte en condición de posibilidad para su vida y su representación. En este sentido, añade que la propuesta ética de Spinoza tiene como propósito sentar las bases de una filosofía de la solidaridad, gracias a que las relaciones y las prácticas sociales son esenciales para perseverar en el ser. No se puede pensar la vulnerabilidad al margen de que los seres humanos vivimos con otros.

En una conferencia ofrecida en la Universidad de Alcalá en junio de 2014, Butler (2014) reconoce que el cuerpo no puede ser pensado sin las condiciones políticas, económicas y éticas, entre otros aspectos, que le permiten tanto su conservación como su desarrollo. La autora aclara que el llamado al conatus spinocista no debe considerarse de un modo egoísta. Si bien parte de nuestra condición es persistir, sobrevivir, entonces tenemos que pensar en la manera cómo se va a entender la interdependencia: o comprendo al otro como un simple medio para la persistencia individual —es decir, que me uno al otro por una mera estrategia práctica y no me preocupo por él-y, en este sentido, la supervivencia precede a la moral; o bien, considero que la existencia no es un privilegio solo mío, sino que es una condición que depende de una relación. Respecto a este último punto, se podría decir que la frontera o el límite con el otro hace parte de la constitución de la identidad y no es un

\footnotetext{
${ }^{19}$ Esta idea va a chocar con el psicoanálisis y la pulsión de muerte.

Performatividad y afectos,

Luz Helena Di Giorgi-Fonseca- p. 107-132
} 
blanco que se puede traspasar por el solo hecho de querer conservar la existencia. El límite es lo que me separa de los demás, no aquello que permite su trasgresión. En este sentido, el cuerpo se define en virtud de sus límites por sus relaciones, que hacen posible su vida.

Hay que advertir que uno de los propósitos de Butler no radica en proteger la precariedad, sino en fomentar la crítica frente a políticas que la piensan desde un marco ontológico diferencial e individualista. La tarea radicaría, entonces, en buscar espacios que intenten generar nuevas formas de aprehensión, que permitan reconocer la precariedad como una condición compartida. La idea es reflexionar acerca de aspectos que posibiliten un intercambio colicional que tenga en cuenta "la vulnerabilidad, la interdependencia, la exposición, la persistencia corporal, el deseo, el trabajo y las reivindicaciones respecto al lenguaje y la pertenencia social" (Butler, 2010: 15), con el fin de incrementar la agencia de los sujetos.

Esa nueva ontología social debe tomarse en serio la responsabilidad con los otros y, especialmente, pensar en los aspectos que hacen posible la vida. Así mismo, fundamentalmente, debe cuestionar las normas excluyentes por las que están determinados los campos de la reconocibilidad. Hay por lo menos dos formas de responsabilidad que rechaza Butler: a) aquellas que justifican las situaciones de violencia en defensa de la soberanía y la seguridad nacional; b) aquellas que se encuentran asociadas a políticas que promueven la eficacia de la democracia en lugares en donde se encuentra ausente. Estas dos formas de responsabilidad responden a una paradoja y, en el fondo, a una irresponsabilidad pues, en lugar de considerar al otro, ya sea en nombre de la seguridad o el bienestar, lo transgreden a través de los medios por los que el poder político democrático quiere alcanzar sus fines.

\section{REFERENCIAS}

Adiche, C. (2014). Americanah. Barcelona: Ramdom House.

Ahmed, S. (2014). The Cultural Politics of Emotion. Edinburgh: University Press.

Berlant, L. (2011). El corazón de la nación. México: Fondo de Cultura Económica.

Butler, J. (1997). Mecanismos psíquicos del poder. Madrid: Cátedra. 
----- (2002). Cuerpos que importan: sobre los límites materiales y discursivos del "sexo". Buenos Aires: Paidós.

----- (2006). Vida precaria. El poder del duelo y la violencia. Buenos Aires: Paidós.

------ (2007). El género en disputa. Barcelona: Paidós.

------ (2008). ¿Qué es la crítica? Un ensayo sobre la virtud de Foucault. En Buden, B. De Nicola et. al. Producción cultural y prácticas instituyentes. Líneas de ruptura y crítica institucional. Madrid: Traficantes de sueños.

------ (2010). Marcos de guerra. Vidas lloradas. Buenos Aires: Paidós.

------ (2014). Repensar la vulnerabilidad y la resistencia. Ponencia presentada en el marco del Xv Simposio de la Asociación Internacional de Filósofas (IAph). 24 de junio de 2014. En Alcalá de Heares: España.

------ (2015). Senses of the subject. Nueva York: Fordham University Press.

El País. (2007). Los poemas secretos de los presos de Guantánamo. El País Internacional. 21 de junio. En http://internacional.elpais.com/internacional/2007/06/21/actualidad/1182376815_850215.html

Departamento Administrativo Nacional de Estadística (DANE). (2005). Demografía y población. GEIH. Recuperado de: https://ww.dane.gov.co/ index.php/estadisticas-por-tema/demografia-y-poblacion/censo-general-2005-1

Falkoff, M. (2008). Poemas de Guantánamo. Madrid: Península.

Figueroa, Mario. (2011). ... ni con el pétalo de una rosa. Razón pública.com. 11 de junio. Recuperado de: http://www.razonpublica.com/index.php/ conflicto-drogas-y-paz-temas-30/3023-ni-con-el-petalo-de-una-rosa. html. Consultado el día 13 de julio de 2013.

Forero, J. (2010). El campesinado colombiano: entre el protagonismo económico y el desconocimiento de la sociedad. Bogotá: Pontificia Universidad Javeriana.

Giddens, A. (1995). La constitución de la sociedad. Buenos Aires: Amorrortu. James, S. (1997). Pasion and Action. Oxford: University Press. 
James, W. (1884). What is an emotion? Mind IX (34): 188-206.

Le Breton, D. (1999). Las pasiones ordinarias. Antropología de las emociones. Buenos Aires: Ediciones Nueva Visión.

Martínez, R.; Del Valle, M.; Gutiérrez, M.; Ramírez, M. (2016). La familia rural y sus formas de diálogo en la construcción de paz en Colombia. Bogotá: Ediciones Unisalle.

Nussbaum, M. (2012). El ocultamiento de lo humano. Repugnancia, vergüenza y ley. Madrid: Katz.

Reddy, W. (1997). Against Contructionis: The Historical Etnography of Emotions. Current Anthropology 38 (3): 327-351.

Soley, P y Sabsay, L. (2012). Judith Butler en disputa. Lecturas sobre la performidad. Madrid: Egales.

Scarry, E. (1985). The body in pain. Nueva York: Oxford University Press.

Sewell, W. (2006). Una teoría de la estructura: Dualidad, agencia y transformación. En Arxius de sociología, n. ${ }^{\circ}$ 14. Pp. 145-176.

Seoane, J. (2004). Del sentido moral a la moral sentimental. El origen sentimental de la identidad y la ciudadanía democrática. Madrid: Siglo XXI.

Spinoza, B. (2009). Ética: Demostrada según el orden geométrico. Trad. Atilano Domínguez. Madrid: Trotta.

Young, I. (2000). La justicia y la política de la diferencia. Madrid. Cátedra. 